УДК 373.211.24

\title{
ОПЫТ ПРИМЕНЕНИЯ АВТОРСКИХ ИНТЕРАКТИВНЫХ ДИДАКТИЧЕСКИХ ИГР ДЛЯ МУЗЫКАЛЬНОГО РАЗВИТИЯ ДОШКОЛЬНИКОВ В УСЛОВИЯХ ДИСТАНЦИОННОГО ОБРАЗОВАНИЯ
}

\author{
Писаревская Маргарита Анатольевна \\ К.П.Н. \\ Гусева Наталия Александровна \\ АНО ВО Московский \\ гуманитарно-экономический университет
}

\begin{abstract}
Аннотация: Данная статья посвящена изучению опыта применения авторских интерактивных дидактических игр для гармоничного развития дошкольников в условиях дистанционного образования. В работе представлены методические рекомендации для успешного применения интерактивных игр в области художественно-эстетического развития детей старшего дошкольного возраста в процессе образовательно-воспитательной деятельности, в условиях дистанционного взаимодействия дошкольного образовательного учреждения с воспитанниками и их родителями (законными представителями); в работе консультационных пунктов, созданных на базе детского сада; в негосударственных образовательных учреждениях, а также в группах семейного воспитания и кратковременного пребывания.
\end{abstract}

Ключевые слова: Дошкольное образование, художественноэстетическое развитие, музыкальная грамота, интерактивные игры, дистанционное взаимодействие.

\section{EXPERIENCE OF USING AUTHOR'S DIDACTIC GAMES FOR MUSICAL DEVELOPMENT OF PRESCHOOL CHILDREN IN THE CONDITIONS OF DISTANCE EDUCATION}

\section{Margarita Pisarevskaya Natalia Guseva}

\begin{abstract}
This article is devoted to the study of the experience of using the author's interactive didactic games for the harmonious development of preschool children in the conditions of distance education. The paper presents methodological
\end{abstract}


recommendations for the successful application of interactive games in the field of artistic and aesthetic development of older preschool children in the process of educational activities, in the conditions of remote interaction of preschool educational institutions with pupils and their parents (legal representatives); in the work of consulting centers established on the basis of a kindergarten; in non-state educational institutions, as well as in groups of family education and short-term stay.

Key words: Preschool education, artistic and aesthetic development, musical literacy, interactive games, remote interaction.

\section{Введение.}

В течение последних нескольких десятилетий дистанционное образование стало глобальным явлением, оказав существенное влияние на характер образования преимущественно взрослого населения во многих странах мира.Спусковым механизмом необходимости активного использования его в системе дошкольного образования стала пандемия коронавируса (COVID-19).Потребность и непрерывность образовательновоспитательного процесса $\mathrm{y}$ детей дошкольного возраста следует рассматривать как самое важное инвестирование в будущее, так как именно этот период является наиболее эффективным, «сенситивным», с точки зрения человечества. Это доказано в международном исследовании нобелевского лауреата по экономике Д. Хекмана. По мнению ученого дошкольный возраст является наиболее эффективным с точки зрения развития человека, и «упущенное время дошкольника» имеет более серьезные последствия, как для развития ребенка, так и для экономики в целом, чем недополученные знания детей-школьников.

Образовательная деятельность, реализуемая в дистанционной форме, предусматривает значительную долю самостоятельных занятий для воспитанников, поэтому необходимо обеспечить методическое и дидактическое сопровождение этого процесса со стороны дошкольной организации. Отвечая задачам ФГОС ДО - сохранить уникальность и самоценность дошкольного детства, интерактивные дидактические игры в виде интерактивной презентации с использованием триггеров наиболее близки современному поколению детей.

Теоретическая актуальность данной работы обусловлена объективной потребностью исследований в вопросе изучения эффективных методов и 
критериев работы в условиях дистанционного взаимодействия с воспитанниками и их родителями (законными представителями) в дошкольных образовательных организациях.

Практическая значимость данного исследования заключается в необходимости описания успешного опыта применения авторских дидактических интерактивных игр для разностороннего развития детей дошкольного возраста в условиях дистанционного взаимодействия.

Объект исследования: опыт работы с использованием авторских дидактических интерактивных игр дошкольной образовательной организации на примере МБДОУ детский сад №15 муниципального образования город Новороссийск в период самоизоляции.

Предмет исследования: авторская дидактическая интерактивная игра (интерактивная презентация с триггерами) как средство, обеспечивающее активную включенность воспитанника в образовательно-воспитательный процесс.

Цель исследования - на примере авторской дидактической интерактивной игры по музыкальному развитию путем эмпирических исследований разработать и описать методические рекомендации по дистанционному (офлайн) обучению длявзаимодействия педагога с воспитанником через его родителей (законных представителей) и критериев соблюдения санитарных норм по продолжительности и количеству занятий с использованием электронных ресурсов.

Гипотеза исследования - дидактическая интерактивная игра по музыкальному развитию способна обогатить детей новыми впечатлениями, способствует формированию музыкальных способностей, в доступной игровой форме помогает разобраться в музыкальной грамоте, соотношении звуков по высоте, развивать тембровый и динамических слух, являясь понятным и доступным инструментом обучения для родителей воспитанников, через которых осуществляется взаимодействие.

Теоретико-методологическую основу составляет нормативно-правовая документация Российского законодательства, а также норм СанПина, регламентирующие использование электронных ресурсов детьми дошкольного возраста $[1,2,3,4,5,6,7,8]$.

База исследований и её участники. Исследование проводилось на базе МБДОУ детский сад №15 муниципального образования город Новороссийск. В исследовании приняли участие 25 детей подготовительной к школе группы. 


\section{1. Описание программы применения интерактивных} дидактических игр для музыкального развития дошкольников в условиях дистанционного образования

Ведущей деятельностью детей в дошкольный период является игра. Современные дети не мыслят себя без компьютера, проводя много часов в интернете, за игрой в компьютерные игры и даже в социальных сетях. Но мало кто из них стремится сознательно овладеть компьютерной техникой и технологиями так, чтобы это действительно могло стать полезным для жизни, творчества и, возможно, для выбора дальнейшей профессии. Поэтому сегодня как никогда актуален вопрос: как и в каком формате включить в жизнь ребенка информационно-коммуникативные технологии с наибольшей пользой и наименьшими рисками?

Поэтому рассматриваемая нами авторская дидактическая игра по музыкальному развитию «Веселые нотки» нашла широкое применение в работе ДОУ (дошкольного образовательного учреждения):

1. В период дистанционного обучения как взаимодействие с воспитанниками и их родителями (законными представителями).

2. В период непосредственной работы с детьми в ДОУ после самоизоляции.

2.1 При организации обогащенной свободной игры детей (ребенок сам проявляет инициативу при выборе занятия);

2.2 При организации индивидуальной работы педагога с детьми согласно индивидуальному маршруту одаренного ребенка или коррекционной работы с воспитанником, имеющим затруднения в данной области развития;

2.3 При организации работы с детьми в группе кратковременного пребывания;

2.4 В работе консультационного пункта при запросе родителей по музыкальному развитию.

2.5 В работе музыкального руководителя,как для изучения нового, так и для закрепления пройденного материала.

Цикл игр, разработанных нами, открывает первое дидактическое пособие «Веселые Нотки», которое представляет собой ряд музыкальных игр, объединенных единым последовательно развивающимся сюжетом: главными героями - семью Веселыми Нотками. Предназначено для детей старшего дошкольного возраста. Целью его является ознакомление воспитанников с музыкальной грамотой в занимательной нетрадиционной форме. 
Вводная игра «Знакомство» (рис. 1)определяет сюжетную линию всего цикла дидактических игр и позволяет детям познакомиться с главными действующими героями. Ноты представлены в виде человечков, что способствует образному восприятию нотной грамоты.

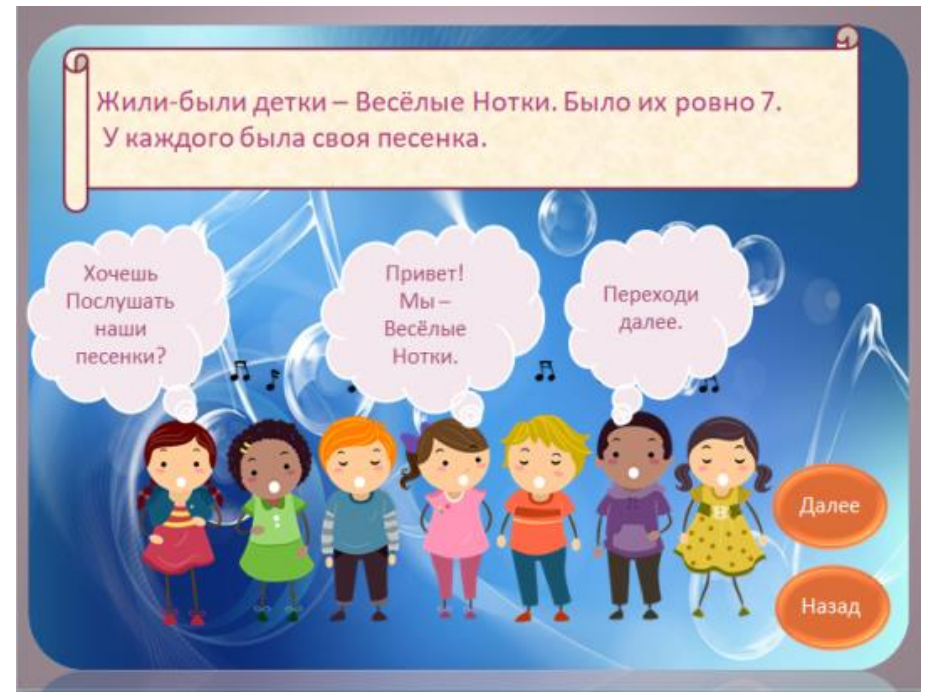

Рис. 1. Вводная игра «Знакомство»

При переходе на данный слайд сюжетная информация, озвученная разными голосами («автором» и несколькими детьми), последовательно появляется на экране. Играющий в занимательной форме познакомится с главными действующими героями и осваивает принцип действия в игре с помощью управляющих кнопок.

В следующей игре «Все на свете знать хотим» (рис. 2)дети в произвольном порядке могут «нажимать» на нотки, звучит фортепианный звук заданной ноты и голосовое пропевание ноты, а также всплывает облачко с изображением ноты на нотном стане. Взрослый акцентирует внимание ребенка на месте «постоянного проживания» ноты на линейках нотного стана. Дополнительно может предложить исполнить «песенки» на одной ноте с различными заданиями (грустная - радостная, с заданным ритмическим рисунком и т.п.). По окончании игры можно перейти на следующий либо предыдущий слайд. 


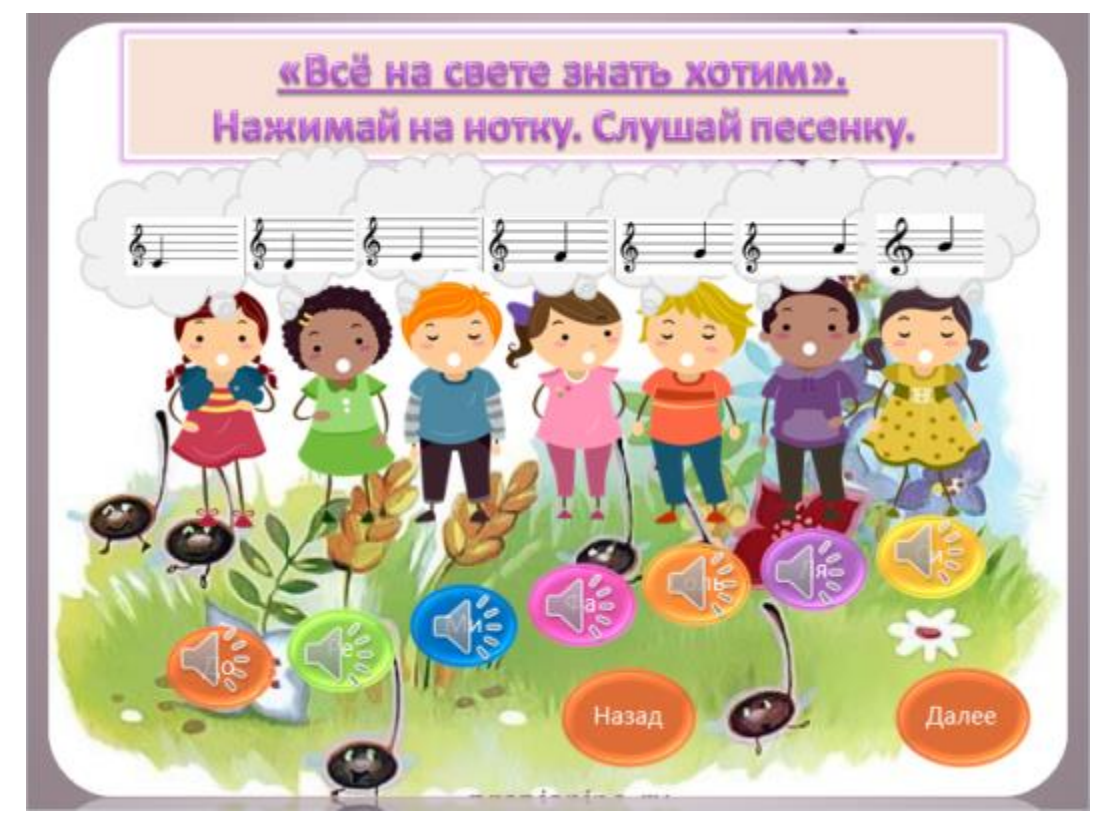

Рис. 2. Игра «Все на свете знать хотим»

Игра способствует ознакомлению детей в занимательной форме с понятиями: нотный стан, скрипичный ключ (или ключ соль); с расположением каждой ноты на нотном стане; развитию музыкального слуха и вокальных данных каждого ребёнка; освоению детьми принципа действия в игре с помощью управляющих кнопок.

Игра «Таинственные знаки» (рис. 3) обеспечивает условия для закрепления знаний детей о расположении каждой ноты на нотном стане. Дети в произвольном порядке либо последовательно выбирают ноту на нотном стане, определяют её расположение относительно линий нотного стана и вспоминают её название. Чтобы проверить свой ответ, они «нажимают» на каждую нотку. Звучит фортепианный звук заданной ноты, голосовое пение, всплывает её буквенное название. От взрослого дети могут получить дополнительное задание исполнить «песенки» на одной ноте с различными заданиями (грустная - радостная, с заданным ритмическим рисунком и т.п.). По окончании игры можно перейти на следующий, либо предыдущий слайд. 


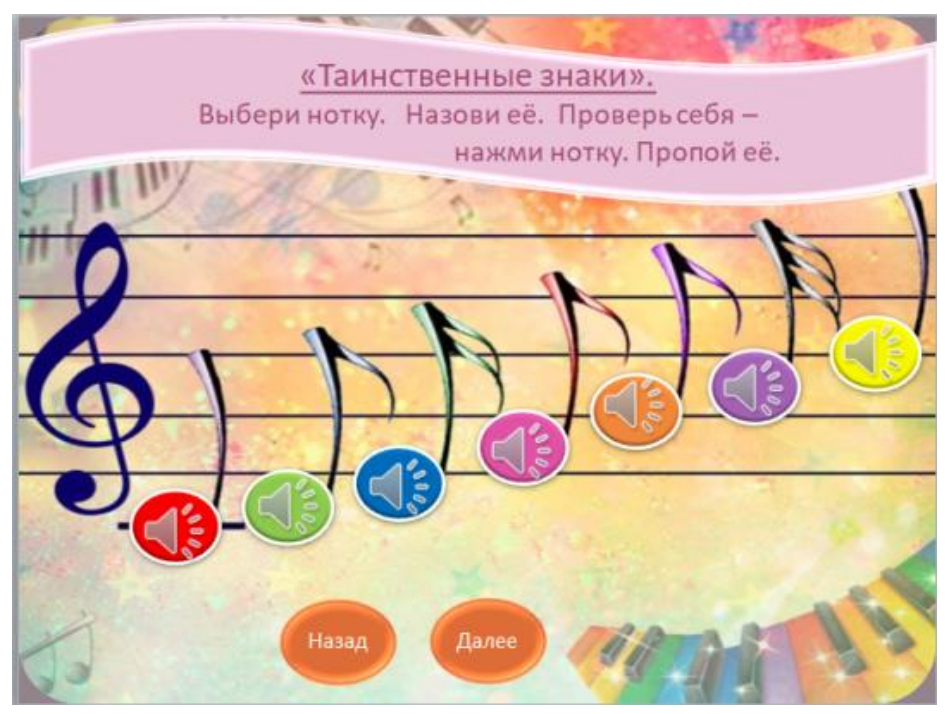

\section{Рис. 3. Игра «Таинственные знаки»}

Выполнение несложных упражнений в данной игре будет способствовать «ситуации успеха», формированию уверенности ребенка в своих силах, развитию музыкального слуха и вокальных данных; освоению детьми принципа действия в игре с помощью управляющих кнопок.

Данный слайд (рис. 4) является заключительным. Он позволяет выйти из игры, либо вернуться на желаемый этап, поддерживает обратную связь на эмоциональную реакцию детей в отношении игры.

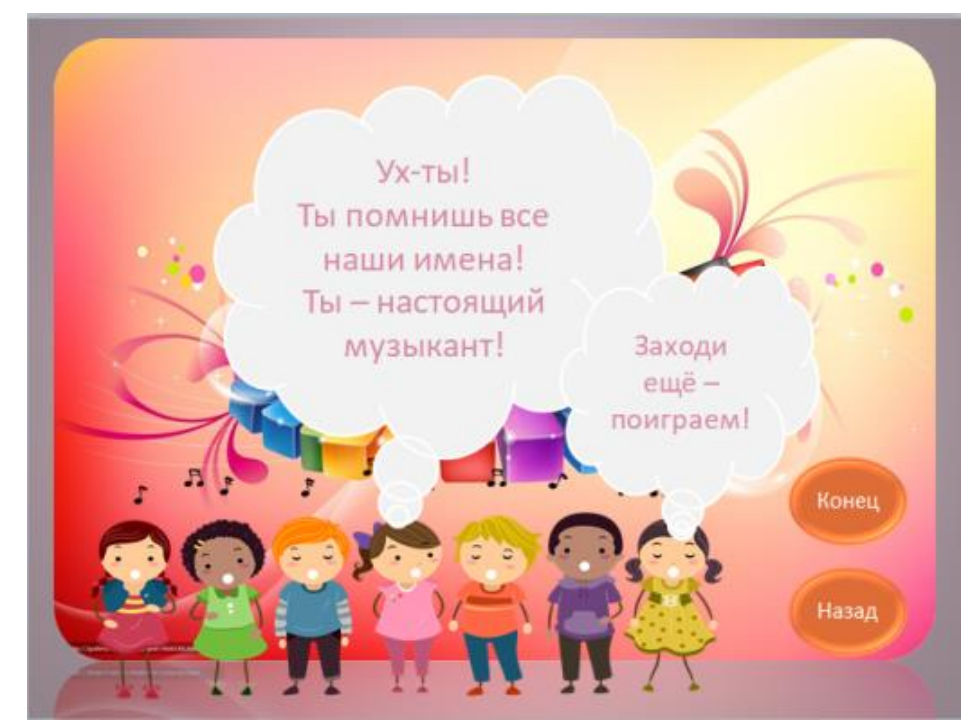

Рис. 4. Заключительный слайд

Данный прием призван стимулировать и поддерживать интерес к игре. Человечки «оживают» в глазах ребенка, обращаясь к нему с экрана. В его воображении отвлеченные названия нот и сказочные герои соединяются, 108 
вызывая желание продолжить знакомство и лучше узнать, как устроен их волшебный мир. В последующих играх данного цикларебят ждут интересные задания: ребусы, упражнение на внимание, на запоминание и др. Ребятишки Веселые Нотки познакомят играющих со своими любимыми домашними питомцами, позволят «поиграть» на музыкальных инструментах.

Возможность самому управлять игрой, которую предоставляют интерактивные игры, обеспечивает деятельностный подход - как основу, средство и главное условие развития личности ребенка. Ребенок учится сам ставить цель, решать задачи, отвечать за результат; воодушевленный игровым познавательным мотивом, он движется к конкретной учебной цели.

\section{Есть ли ограничения в количестве занятий с использованием} электронных ресурсов и их продолжительности? Да, и они строго регламентированы. Требования к ним изложены в инструктивнометодическом письме Минобразования России №65/23-16 от 14.03.2000«О гигиенических требованиях к максимальной нагрузке на детей дошкольного возраста в организованных формах обучения» в пункте 5: «Занятия с использованием компьютеров для детей 5-6 лет не должны проводиться чаще двух раз в неделю».Дети 3-4 лет могут проводить за компьютером не более 5 минут, у детей 4-6 лет занятия на компьютере не превышают 10минут.Начиная с 6-ти летнего возраста, ребенок может использовать компьютер до15 минут в день с обязательным перерывом на динамическиепаузы. Об этом в обязательном порядке педагог уведомляет родителей (законных представителей) воспитанников.

2. Методические рекомендации для дистанционного взаимодействия педагога с воспитанниками и их родителями (законными представи-телями) при ознакомлении с интерактивной дидактической игрой, представленной в форме интерактивной презентации с триггерами

1. Ознакомление родителей с гигиеническими требованиями к максимальной нагрузке на детей дошкольного возраста при электронных организованных формах обучения.

2. Описание совместной разнообразной деятельности взрослого и ребенка.

3. Перечень дополнительных заданий к слайдам/интерактивным играм с указанием номера слайда/названия игры.

4. Примерные вопросы для обсуждения игры. Рефлексия. 
Путем эмпирического исследованиф, в ходе наблюдений и бесед с воспитанниками и их родителями (законными представителями) были изучены их предпочтения в формах дистанционного взаимодействия. Результаты исследования представлены в диаграмме (рис. 5):

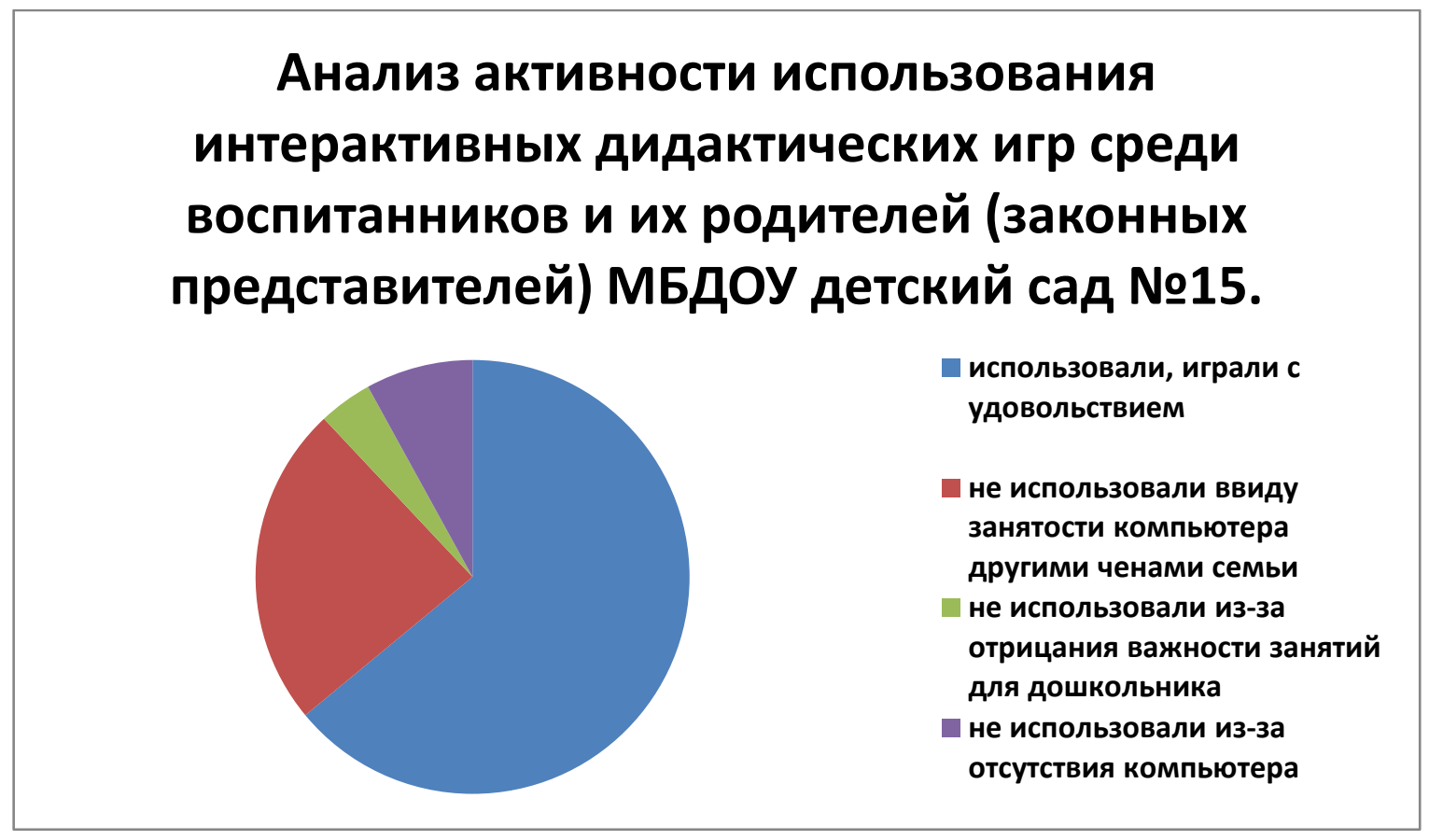

Рис. 5. Результаты исследования активности использования интерактивных игр

Результаты данного исследования зависели от родителей воспитанников, так как основным условием использования игры являлось наличие компьютера и предоставление ребенку возможности играть. Если в семье работа кого-либо из родителей была связана с компьютером, а также имелись дети-школьники, то потребности ребенка-дошкольника в реализации своего развития посредством интерактивных игр отодвигались на последний план. Кроме того, есть семьи, которые по идейным либо по финансовым соображениям не имеют в наличии компьютеров, ноутбуков, планшетов. Согласно опросу, лишь 64\% (16 человек) детей имели возможность играть в данную дидактическую игру. 
Для дальнейшего изучения вопроса важным фактором исследования был тот факт, насколько возникает желание воспользоваться игрой повторно. Полученные данные представлены в таблице (рис. 6.):

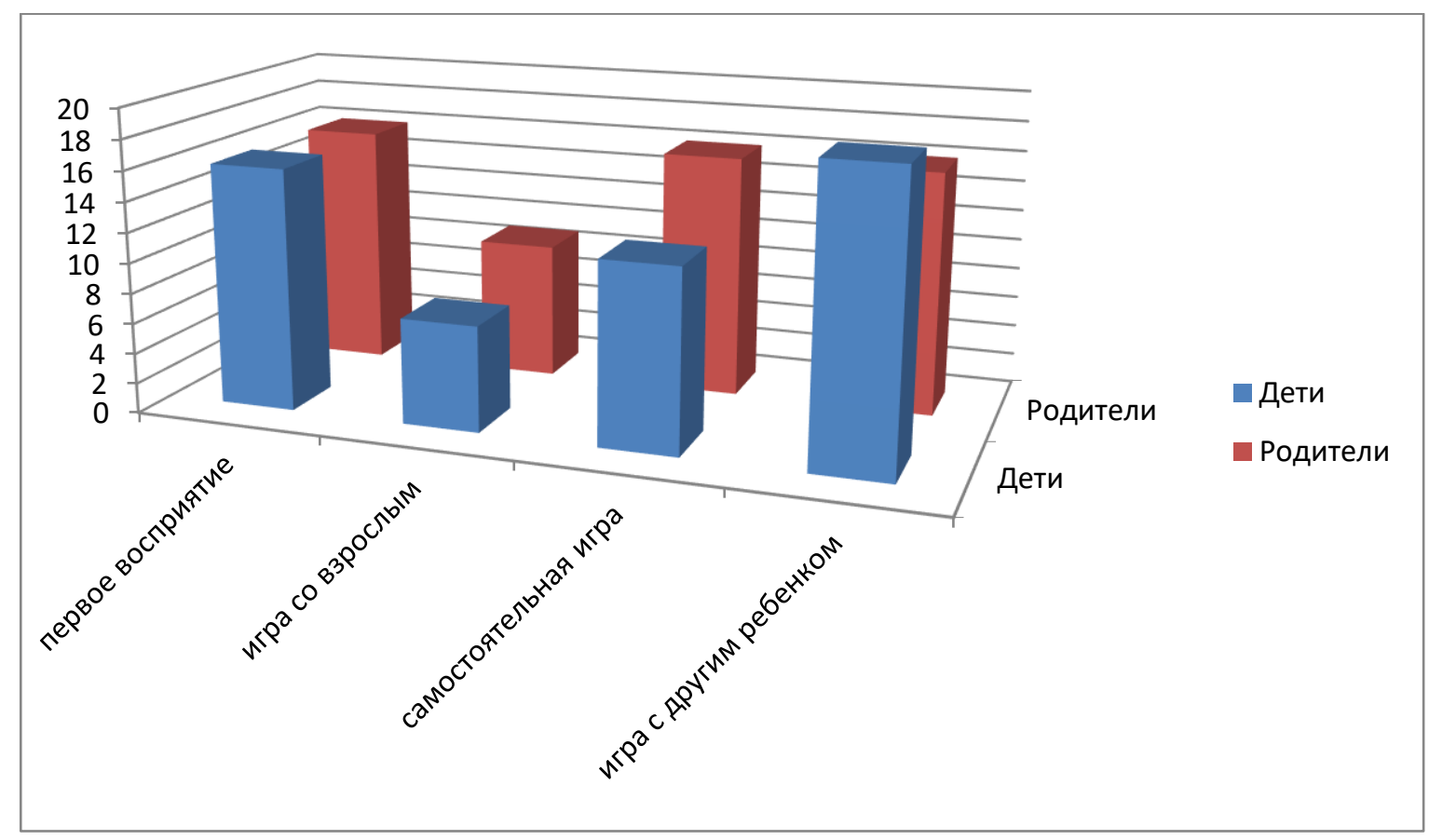

Рис. 6. Результаты исследования повторного использования интерактивных игр

Данное исследование проводилось в два этапа: во время самоизоляции и после выхода из нее. В результате анализа были получены данные о том, что интерактивные дидактические игры как инновационный метод, нестандартный подход для повышения эмоционального отклика, мотивации ребенка получили высокую оценку, как детей, так и родителей. Для многих опрошенных родителей важным критерием удобства использования интерактивных игр являлась возможность для детей играть самостоятельно, без помощи взрослых либо с другим ребенком. По окончании периода самоизоляции педагогами была организована работа с дидактической интерактивной игрой в группе в следующих формах:

1. При организации обогащенной свободной игры детей (ребенок сам проявляет инициативу при выборе вида деятельности);

2. При организации индивидуальной работы педагога с детьми согласно индивидуальному маршруту одаренного ребенка или коррекционной работы с воспитанником, имеющим затруднения в данной области развития; 
3. При организации работы с детьми в группе кратковременного пребывания.

Для детей подача информации в форме дидактической интерактивной игры оказалась наиболее предпочтительной, органичной. Это объясняется навыком современных детей считывать и воспринимать информацию. Задача педагога - учитывая эти особенности, обеспечить психолого-педагогические условия, то есть построение образовательной деятельности на основе взаимодействия взрослых с детьми, ориентированного на интересы и возможности каждого ребенка. Особенно хотелось отметить организованные формы взаимодействия «учитель - ученик», когда один ребенок обучал другого правилам игры, и «игра с другим ребенком». Эти формы имели не только большую педагогическую ценность, но и вызвали яркий эмоциональный отклик среди детей.

Результаты данного исследования подводят нас к выводам, что использование информационно-коммуникативных технологий имеет ряд неоспоримых преимуществ:

- ИКТ позволяют работать как индивидуально, так и в группах либо подгруппах;

- ИКТ продвигает ребенка в общем развитии;

- ИКТ несёт в себе образный тип информации, понятный детям;

- ИКТ - движение, звук, мультипликация - надолго привлекают внимание ребенка;

- ИКТ является отличным средством для решения образовательных задач:обогащает детей новыми впечатлениями, способствует формированию музыкальных способностей, в доступной игровой форме помогает разобраться в музыкальной грамоте, соотношении звуков по высоте, развивает тембровый и динамических слух, являясь понятным и доступным инструментом обучения для родителей воспитанников, через которых осуществляется взаимодействие.

\section{Список литературы}

1. Федеральный закон от 29 декабря 2012 г. N273-Ф3 «Об образовании в Российской Федерации» (ст.13 п.2, ст.15, ст.16, ст.17, ст. 41п.5).

2. Приказ Минпросвещения России от 17.03.2020 №103 «Об утверждении временного порядка сопровождения реализации образовательных программ начального общего, основного общего, среднего 
общего образования, образовательных программ среднего профессионального образования и дополнительных общеобразовательных программ с применением электронного обучения и дистанционных образовательных технологий».

3. Приказ Министерства образования и науки Российской Федерации от 23 августа 2017 года № 816 «Об утверждении Порядка применения организациями, осуществляющими образовательную деятельность, электронного обучения, дистанционных образовательных технологий при реализации образовательных программ».

4. Письмо Министерства образования и науки Российской Федерации от 21 апреля 2015 года № ВК-1013/06 «Онаправлении методических рекомендаций по реализации дополнительных профессиональных программ (с Методическими рекомендациями по реализации дополнительных профессиональных программ с использованием дистанционных технологий, электронного обучения и в сетевой форме)» (п.2.2.).

5. Федеральный закон от 27 июля 2006 г. №149-Ф3 «Об информации, информационных технологиях и о защите информации» (с изменениями идополнениями).

6. Указ президента Российской Федерации от 02.04.2020 г. №239 «О мерах по обеспечению санитарно- эпидемиологического благополучия населения на территории с распространением новой коронавирусной инфекции (COVID - 19)».

7. СанПиН 2.2.2/2.4.1340-03 Гигиенические требования к персональным электронно-вычислительным машинам и организации работы. Постановление от 13 июня 2003 года N118 «О введении в действие санитарноэпидемиологических правил и нормативов» СанПиН 2.2.2/2.4.1340-03 (с изменениями на 21 июня 2016года).

8. Письмо Минобразования РФ №65/23-16 от 14.03 .2000 «Онаправлении инструктивно-методического письма «О гигиенических требованиях к максимальной нагрузке на детей дошкольного возраста в организованных формах обучения».

(C) Н.А. Гусева, 2020 